\title{
NILAI-NILAI PENDIDIKAN KARAKTER UNTUK ANAK USIA DINI DALAM FILM “NUSSA"
}

\author{
Diah Novita Fardani ${ }^{1}$, Yorita Febry Lismanda ${ }^{2}$ \\ ${ }^{1}$ IAIN Surakarta, ${ }^{2}$ Universitas Islam Malang (UNISMA) \\ e-mail: ${ }^{1}$ diahnovita.novy@gmail.com ,2yorita.febry@unisma.ac.id,
}

Diterima: 26 November 2019 I Direvisi: 13 Desember 2019 I Disetujui: 31Desember 2019 (C)2019 Pendidikan Guru Raudhatul Atfhal Fakultas Agama Islam Universitas Islam Malang

\begin{abstract}
Early Childhood has a variety of interests, one of them is the fondness of watching television shows that are animated cartoons. At an early age, children have a strong tendency to mimic everything they see. This becomes important considering that a lot of animated cartoon films are shown and are often seen by children which certainly affects the character and personality of children. This study aims to determine the values of character education for early childhood contained in the animated film "Nussa". In carrying out this study using a qualitative descriptive approach by analyzing the contents of four randomly selected episodes. The results of this study found that educational values characters for early childhood contained in the four episodes of the animated film "Nussa" are very diverse, among the character values contained such as religious, hard work, independent, friendly and communicative, honest, caring socially, creatively, disciplined, rewarding achievement, and responsibility.
\end{abstract}

Keywords: Character Education, Nussa, Early Childhood Education.

\section{A. Pendahuluan}

Keberhasilan pendidikan karakter di Indonesia sedang diuji dengan adanya permasalahan dan kasus yang membelit negeri ini. Permasalahan itu mencakup berbagai aspek kehidupan, tertuang dalam berbagai tulisan di media cetak, wawancara, dialog, dan gelar wicara di media elektronik. Dicontohkan, masih hangat diberitakan terdapat kasus penganiayaan terhadap Audrey gadis SMP yang kemudian setelah di usut ternyata korban juga seorang yang kurang baik. Tidak lama dengan kasus itu datanglah kasus kedua yaitu berita salah satu artis kenamaan yang terjerat masalah prostitusi. Kasus ini masih hangat disusul dengan aksi people power pasca ditetapkannya Jokowi sebagai presiden terpilih dalam

This work is licensed under Creative Commons Attribution Non Commercial 4.0 International License Available online on: http://riset.unisma.ac.id/index.php/fai/index 
pemilu 2019. Jika semua berita tersebut benar adanya, tampaknya banyak kalangan yang menyesalkan. Tiga kasus tersebut sangat menguji pendidikan karakter di Indonesia.

Selain di media massa, para ahli dan pengamat pendidikan maupun sosial berbicara tentang persoalan karakter di berbagai forum seminar, baik pada tingkat lokal, nasional, maupun internasional. Persoalan yang muncul di masyarakat seperti korupsi, kekerasan, kejahatan seksual, perusakan, perkelahian massa, kehidupan ekonomi yang konsumtif, kehidupan politik yang tidak produktif, dan sebagainya menjadi tema hangat di media massa, seminar, dan di berbagai kesempatan. Berbagai alternatif pemecahan pun ditelorkan seperti peraturan, undang-undang, dan penerapan hukum yang lebih kuat. Alternatif lain yang dikemukakan untuk mengatasi masalah di atas adalah pendidikan. Pendidikan dinilai dapat menjadi alternatif yang bersifat preventif karena pendidikan membangun generasi baru bangsa yang lebih baik. Sebagai alternatif yang bersifat preventif, pendidikan diharapkan dapat mengembangkan kualitas generasi penerus bangsa dalam berbagai aspek yang dapat memperkecil dan mengurangi penyebab berbagai masalah budaya dan karakter bangsa. Memang disadari bahwa hasil dari pendidikan akan terlihat dampaknya dalam waktu yang tidak segera, tetapi memiliki daya tahan dan dampak yang kuat di masyarakat.

Tidak heran jika kemudian di dalam Pasal 3 UU RI No. 20 Tahun 2003 tentang Sistem Pendidikan Nasional disebutkan, "Pendidikan nasional berfungsi mengembangkan dan membentuk watak serta peradaban bangsa yang bermartabat dalam rangka mencerdaskan kehidupan bangsa, bertujuan untuk berkembangnya potensi peserta didik agar menjadi manusia yang beriman dan bertakwa kepada Tuhan Yang Maha Esa, berakhlak mulia, sehat, berilmu, cakap, kreatif, mandiri, dan menjadi warga negara yang demokratis serta bertanggung jawab". Pasal inilah yang sepertinya selama ini dijadikan sebagai salah satu tonggak untuk memayungi berjalannya pendidikan karakter di semua jenjang pendidikan di Indonesia. Gaung pendidikan karakter memang masih membahana, mulai dari jenjang prasekolah, sekolah dasar, sekolah menengah, hingga pendidikan tinggi. Bahkan, pendidikan karakter juga sudah menjadi konsumsi harian di pendidikan nonformal. Beragam judul buku pun bermunculan terkait teori dan praktik pendidikan karakter. Beragam sarana dan media juga disiapkan untuk menyukseskan pendidikan karakter. Telah prominen bahwa media pembelajaran ada yang berbentuk audio, visual, dan audiovisual. Sesuai penuturan sejumlah guru Pendidikan Anak Usia Dini (PAUD) di Surakarta, ketiga jenis media itu telah merambah pula di PAUD. Contoh media audio yang digunakan adalah kumpulan MP3 lagu anak-anak dan perekam (recorder) di HP. Media visual yang 
dimanfaatkan seperti gambar binatang, buah, alat transportasi, dan lain-lain. Media audiovisual misalnya video film kartun, video binatang, video profesi, dan sebagainya.

Media pembelajaran berupa film, misalnya, memang menjadi salah satu media yang sering digunakan di PAUD belakangan ini, terlebih di PAUD yang memiliki aksesibilitas untuk itu. Dikarenakan tuntutan dari pemerintah untuk menyisipkan nilai-nilai karakter di PAUD, maka guru pun musti pintar memilih film yang akan dimanfaatkan sebagai media penanaman karakter. Sayangnya, tidak semua film dapat digunakan untuk itu. Implikasinya, guru dan orangtua perlu berhati-hati di dalam menentukan film yang akan diperlihatkan kepada anak-anak. Pantas dan tidak pantasnya film untuk ditonton memang masih menuai pro dan kontra. Namun, budaya dan norma di Indonesia telah secara implisit memperlihatkan bahwa ada hal-hal yang kudu dipertimbangkan bagi para orangtua ketika televisi di rumah menyala dan dinikmati buah hatinya. Berdasarkan hasil mini survei kepada mahasiswa/i yang sedang kuliah di Jurusan PIAUD IAIN Surakarta, diperoleh data bahwa diantara adegan di film yang kurang pas untuk dilihat anak-anak adalah kekerasan, perselisihan dan permusuhan, peperangan dan pembunuhan, gosip, dan percintaan. Di sisi lain, adegan yang patut dilihat seperti persahabatan, olahraga, aktivitas prestisius, dan kegiatankegiatan yang mencerminkan upaya mencintai lingkungan.

Hal tersebut dipertegas dengan regulasi pemerintah berupa UU RI No. 32 Tahun 2002 tentang Penyiaran. Di Pasal 35 dipaparkan bahwa Isi siaran harus sesuai dengan asas, tujuan, fungsi, dan arah siaran. Sementara di Pasal 36 dituangkan penjelasan sebagai berikut:

1. Isi siaran wajib mengandung informasi, pendidikan, hiburan, dan manfaat untuk pembentukan intelektualitas, watak, moral, kemajuan, kekuatan bangsa, menjaga persatuan dan kesatuan, serta mengamalkan nilai-nilai agama dan budaya Indonesia.

2. Isi siaran dari jasa penyiaran televisi, yang diselenggarakan oleh Lembaga Penyiaran Swasta dan Lembaga Penyiaran Publik, wajib memuat sekurangkurangnya $60 \%$ (enam puluh per seratus) mata acara yang berasal dari dalam negeri.

3. Isi siaran wajib memberikan perlindungan dan pemberdayaan kepada khalayak khusus, yaitu anak-anak dan remaja, dengan menyiarkan mata acara pada waktu yang tepat, dan lembaga penyiaran wajib mencantumkan dan/atau menyebutkan klasifikasi khalayak sesuai dengan isi siaran.

4. Isi siaran wajib dijaga netralitasnya dan tidak boleh mengutamakan kepentingan golongan tertentu. 
5. Isi siaran dilarang:

a. bersifat fitnah, menghasut, menyesatkan dan/atau bohong;

b. menonjolkan unsur kekerasan, cabul, perjudian, penyalahgunaan narkotika dan obat terlarang; atau

c. mempertentangkan suku, agama, ras, dan antargolongan.

6. Isi siaran dilarang memperolokkan, merendahkan, melecehkan dan/atau mengabaikan nilai-nilai agama, martabat manusia Indonesia, atau merusak hubungan internasional.

Di Pasal 48 juga disebutkan bahwa standar isi siaran sekurang-kurangnya berkaitan dengan:

1. rasa hormat terhadap pandangan keagamaan;

2. rasa hormat terhadap hal pribadi;

3. kesopanan dan kesusilaan;

4. pembatasan adegan seks, kekerasan, dan sadisme;

5. perlindungan terhadap anak-anak, remaja, dan perempuan;

6. penggolongan program dilakukan menurut usia khalayak;

7. penyiaran program dalam bahasa asing;

8. ketepatan dan kenetralan program berita;

9. siaran langsung; dan

10. siaran iklan

Diketahui bahwa film yang pada umumnya ditonton oleh anak-anak, terlebih anak usia dini (usia 4-6 tahun), adalah film kartun. Film adalah lakon (cerita) gambar hidup (Salim, 2002). Kartun merupakan film yang menciptakan khayalan gerak sebagai hasil pemotretan rangkaian gambar yang melukiskan perubahan posisi. Kartun juga merupakan gambar dengan penampilan yang lucu, berkaitan dengan keadaan yang sedang berlaku. Dari ini kemudian dapat dikatakan bahwa film kartun adalah film hiburan dalam bentuk gambar lucu yang mengisahkan tentang binatang dan sebagainya. Istilah film kartun tidak jarang dipersamakan dengan film animasi. Animasi diartikan sebagai acara televisi yang berbentuk rangkaian lukisan atau gambar yang digerakkan secara mekanik elektronis sehingga tampak di layar menjadi bergerak.

Selanjutnya diketahui pula bahwa film kartun yang ditayangkan di Indonesia ada yang berasal dari dalam negeri dan luar negeri. Kartun luar negeri yang masih digemari antara lain adalah Upin \& Ipin, Tayo, SpongeBob SquarePants, Angry Birds, Marsha \& the Bear, dan Shaun The Sheep. Sedangkan kartun dalam negeri yang masih seringkali ditayangkan adalah Keluarga Somat, Lorong Waktu, Bilu Mela, Adit \& Sopo Jarwo, dan Nussa. 
Jika memperhatikan sejumlah film kartun tersebut-dan bahkan film non kartun pun, bukan tidak mungkin aktivitas apapun yang dilakukan oleh karakter/tokoh di film akan sedikit banyak ditiru oleh anak-anak. Implikasinya, orangtua akan sangat senang apabila anaknya berhasil meniru karakter yang bagus. Sebaliknya, orangtua akan galau ketika karakter yang ditiru adalah sosok yang melakukan kegiatan negatif. Padahal, Maria Montessori sempat mengemukakan bahwa anak usia dini memiliki "The Absorbent Mind", yakni pikiran penyerap yang setiap saat menyerap informasi (ucapan dan/atau tindakan) yang masuk ke dalam memorinya (Britton, 1992). Oleh karena itu, Nussa dan Rara nampaknya adalah peluang untuk menjadi media menanamkan karakter sejak dini kepada anak. Film ini masuk ke trending YouTube di Indonesia. Bahkan kabar baik sekarang film ini sudah masuk kedalam TV di Indonesia yaitu Net TV ketika menjelang berbuka puasa selama ramadhan 2019. Ini memberi peluang kepada anak-anak untuk menontonnya sembari menunggu berbuka puasa dengan keluarga.

Berangkat dari penjelasan di atas, permasalahan pada tulisan ini dapat dirumuskan menjadi "Nilai-nilai karakter apa saja yang ada di dalam film Nussa yang dapat ditanamkan pada anak usia dini?". Sesungguhnya kajian terkait pendidikan karakter sudah beberapa kali dilakukan. Tapi tema tentang pendidikan karakter tidak ada bosannya ketika harus ditelaah lebih mendalam sekaligus menyesuaikan dengan kebutuhan pada zaman sekarang ini. Jadi pendidikan karakter akan berubah seiring zaman terlebih du era Revolusi 4.0 ini. Courtney Tyra, antara lain, pernah melakukan riset dengan temuan yang menunjukkan bahwa literatur anak-anak merupakan sarana yang (amat mungkin) dapat digunakan untuk secara efektif mengajarkan pendidikan karakter kepada mereka (Ismail \& Hidayatulloh, 2014). Berikutnya dari penelitian Endang Mulyatiningsih didapati inti sari bahwa model pendidikan untuk pembentukan karakter pada usia anak-anak diantaranya dilakukan melalui aktivitas bercerita, bermain peran, dan kantin kejujuran (Mulyatiningsih, tt). Vivit Risnawati pernah melakukan kajian yang memperoleh temuan bahwa Sentra Main Peran berhasil dioptimalkan penggunaannya untuk meningkatkan pendidikan karakter anak di TK Citra AlMadina Padang (Risnawati, 2012). Sementara itu, Siti Nurul Nur Hidayati pernah melakukan kajian yang medapatkan hasil bahwa media Film Kartun "Adit dan Sopo Jarwo" terbukti efektif untuk meningkatkan kemampuan berbicara pada anak usia 4 - 5 Tahun TK Salma Insani Kota Kediri (Hidayati, 2016). Darmu'in, di kesempatan berbeda, menghasilkan temuan berupa deskripsi pembelajaran pendidikan karakter yang dilakukan di TK Negeri Pembina Semarang, yakni melalui: (1) Keteladanan dan Pembiasaan, (2) Terintegrasi dengan Pembelajaran, 
(3) Pendidikan karakter di luar satuan pendidikan, (4) Pengembangan Budaya Satuan Pendidikan, (5) Pengintegrasian Pendidikan Karakter dalam Semua Aspek Pengembangan, (6) Integrasi Pendidikan Karakter dalam Kegiatan Rutin, (7) Pemberdayaan dan Pembudayaan Pendidikan Karakter, (8) Penguatan Pendidikan Karakter (Darmu'in, 2013).

\section{B. Metode}

Berdasarkan pokok permasalahan dan subjek penelitian yang diteliti, maka penelitian ini menggunakan penelitian deskriptif kualitatif. Peneliti berupaya meneliti perilaku atau tindakan dan motivasi anak yang muncul setelah menonton film "Nussa" menggunakan acuan yang ada. Selanjutnya peneliti berupaya menjelaskan dengan deskripsi yang lengkap berbagai karakter yang terbentuk dari pembiasaan perilaku tersebut. Kehadiran peneliti menjadi poin penuh yang mendasari keberhasilan penelitian ini. Mulai dari perencanaan, pengumpulan dan analisis dara,sampai dengan penafsiran dan penyimpulan dilakukan oleh peneliti sendiri. Data dan sumber data data yang diambil oleh peneliti adalah data nilai-nilai pendidikan karakter untuk anak usia dini dalam film"Nussa" yang berpedoman pada sejumlah karakter pada Pedoman Pendidikan Karakter pada PAUD (Dirjen PAUDNI Kemdiknas, 2012) dan Pengembangan Budaya dan Karakter Bangsa: Pedoman Sekolah (Pusat Kurikulum, 2010). Sumber data penelitian ini adalah tayangan"Nussa" 4 episode yang dipilih secara random.

\section{Hasil dan Pembahasan \\ 1. Pendidikan Karakter}

Terdapat beragam definisi mengenai pendidikan karakter yang dapat dijadikan sebagai rujukan. Dalam Pedoman Pendidikan Karakter pada Pendidikan Anak Usia Dini, misalnya, pendidikan karakter dimaksudkan sebagai upaya penanaman nilai-nilai karakter kepada anak didik yang meliputi pengetahuan, kesadaran atau kemauan, dan tindakan untuk melaksanakan nilai-nilai kebaikan dan kebajikan, kepada Tuhan YME, diri sendiri, sesama, lingkungan maupun kebangsaan agar menjadi manusia yang berakhlak (Dirjen PAUDNI Kemdiknas, 2012). Kemudian, dengan mengambil pernyataan David Elkind dan Freddy Sweet, Joko Nurkamto menguraikan: Character education is the deliberate effort to help people understand, care about, and act upon core ethical values. When we think about the kind of character we want for our children, it is clear that we want them to be able to judge what is right, care deeply about what is right, and then do what they believe to be right, even in the face of pressure from without and temptation from within (Nurkamto, 2011). 
Sementara itu, mengutip pemaparannya Sue Winton, Samani dan Hariyanto menyebutkan bahwa pendidikan karakter adalah upaya sadar dan sungguhsungguh dari seorang guru untuk mengajarkan nilai-nilai kepada para siswanya (Samani \& Hariyanto, 2011). Mereka juga mengutip definisi yang ditawarkan oleh Scerenko bahwa pendidikan karakter dapat dimaknai sebagai upaya sungguhsungguh dengan cara mana ciri kepribadian positif dikembangkan, didorong, dan diberdayakan melalui keteladanan, kajian (sejarah dan biografi para bijak dan pemikir besar), dan praktik emulasi (usaha maksimal untuk mewujudkan hikmah dari apa-apa yang diamati dan dipelajari) (Samani \& Hariyanto, 2011).

Pada tahapan proses pendidikan yang dilewati manusia, sesungguhnya pendidikan karakter dapat ditanamkan sejak dini, yakni dari usia 0-6 tahun. Urgensi dimulainya pendidikan karakter sejak dini ditegaskan oleh Masnur Muslich. Dengan mengutip pernyataan Freud, ia menjelaskan bahwa karakter yang berkualitas perlu dibentuk dan dibina sejak usia dini. Usia dini merupakan masa kritis (critical period) bagi pembentukan karakter seseorang. Kegagalan penanaman kepribadian yang baik di usia dini akan membentuk pribadi yang bermasalah di masa dewasanya kelak. Jadi kesuksesan orangtua dalam membimbing anaknya sangat menentukan kesuksesan anak di kehidupan sosialnya ke depan (Muslich, 2011). Untuk mempermudah guru dalam menanamkan karakter pada anak usia dini, berikut ini disuguhkan sejumlah karakter sebagaimana dituangkan di dalam Pedoman Pendidikan Karakter pada PAUD (Dirjen PAUDNI Kemdiknas, 2012) dan di dalam Pengembangan Budaya dan Karakter Bangsa: Pedoman Sekolah (Pusat Kurikulum, 2010).

\section{Tabel 1}

\section{Nilai-Nilai Karakter}

\begin{tabular}{|c|c|}
\hline $\begin{array}{l}\text { - Kecintaan terhadap Tuhan } \\
\text { YME/religius } \\
\text { - } \text { Kejujuran } \\
\text { - } \text { Disiplin } \\
\text { - Toleransi dan cinta damai } \\
\text { - Percaya diri } \\
\text { - } \text { Mandiri } \\
\text { - Rasa ingin tahu } \\
\text { - } \text { Bersahabat \& komunikatif } \\
\text { - Tolong menolong, } \\
\text { kerjasama, dan gotong } \\
\text { royong (peduli sosial) }\end{array}$ & $\begin{array}{l}\text { - } \text { Demokratis } \\
\text { - } \text { Gemar membaca } \\
\text { - } \text { Henghargai prestasi } \\
\text { santun dan sopan } \\
\text { - Tanggung jawab } \\
\text { - Kerja keras } \\
\text { - Kepemimpinan dan } \\
\text { - Keadilan } \\
\text { - Kreatif } \\
\text { - } \text { Rendah hati } \\
\text { - Cinta bangsa dan } \\
\text { tanah air }\end{array}$ \\
\hline
\end{tabular}

Thufuli: Volume 1 Nomor 2, Tahun 2019 


\section{Film Nussa}

Film animasi kartun Nussa menceritakan tentang Rara seorang gadis cilik berumur 5 tahun yang sangat suka bermain balap mobil. Tidak hanya itu dia juga suka bermain lainnya. Kemudian Nussa adalah seorang kakak yang sangat sayang kepada adiknya yaitu Rara.

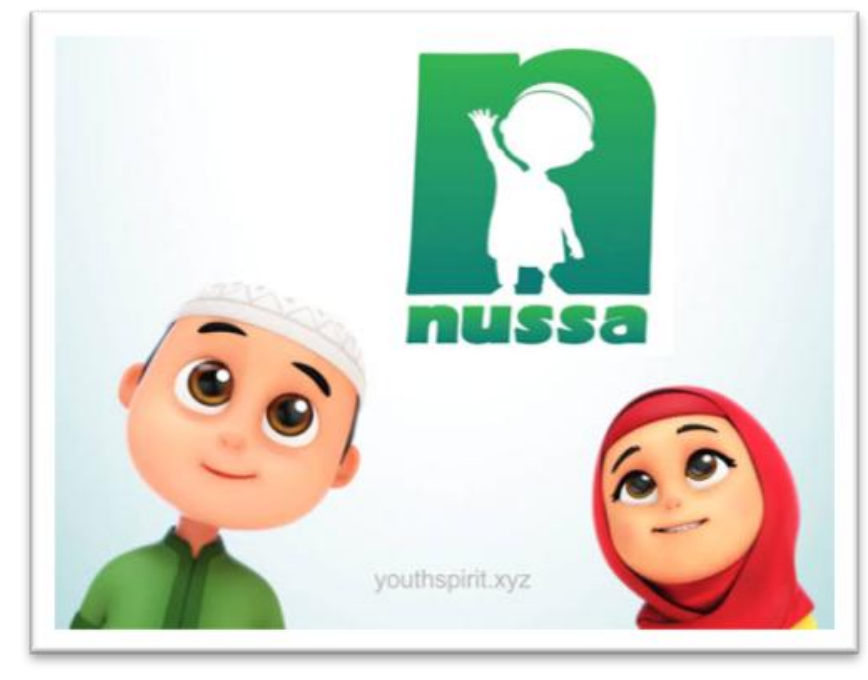

Gambar 1. Tokoh utama Nussa

Film Nussa ini dirasa menjadi penyelamat kekhawatiran orang tua terhadap tontonan jaman sekarang yang beredar. Kurangnya tontonan yang edukatif menjadi kekhawatiran tersendiri bagi orang tua, tetapi hadirnya film Nussa menjadi solusi utama mengenai kekhawatiran orang tua dengan tontonan jaman sekarang. Film ini dirasa tidak kalah kualitas dengan film lain seperti misal film Upin \& Ipin maupun Adit \& Sopo Jarwo. Bahkan dikabarkan film Nussa ini nanti akan dibuat dengan bahasa-bahasa lain seperti bahasa Arab, bahasa Inggris dan bahasa-bahasa internasional lainnya. Dan kabar hangat lagi bagi para orang tua bahwa film Nussa tayang di Net Tv selama ramadhan menjelang berbuka puasa. Hal ini lebih memudahkan juga bagi orang tua atau anaknya untuk mengaksesnya.

Animasi ini adalah produksi dari rumah animasi The Little Giantz yang di gagas oleh Mario Irwinsyah dengan berkolaborasi bersama 4 Stipe Production. Mendapat sambutan hangat dari masyarakat Indonesia, episode pertama Nussa sudah mencapai 2.2 juta penonton dan memiliki lebih dari 400 ribu subscriber. Bahkan menduduki posisi trending YouTube di Indonesia. Dari segi pengisi suara, tokoh Nussa di dubbing oleh Muzzaki Ramdhan. Dia adalah seorang aktor cilik yang pernah bermain di beberapa film Indonesia, salah satunya adalah film The 
Returning (2018). Karakter Rara di dubbing oleh Aysha Ocean Fajar. Dia adalah seorang gadis kecil berusia 4 tahun yang lahir di Dubai.

Karakter/tokoh di dalam film ini adalah:

a. Nussa

Digambarkan sebagai seorang laki-laki yang berpakaian gamis lengkap dengan kopiyah putihnya. Dia diciptakan sebagai tokoh penyandang disabiitas. Hal ini tampak pada kaki kiri nussa yang menggunakan kaki palsu.

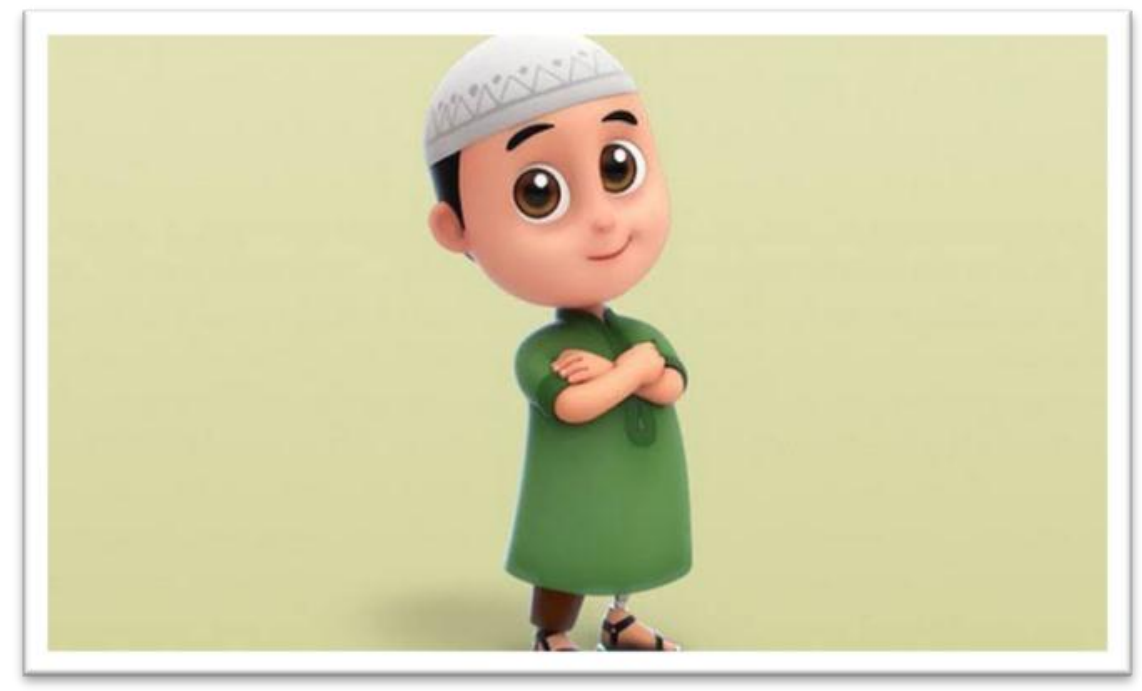

Gambar 2. Tokoh Nussa

b. Rara

Digambarkan sebagai adik Nussa yang berusia 5 tahun dengan menggunakan gamis dan jilbab yang sangat ceria dan menggemaskan suaranya.

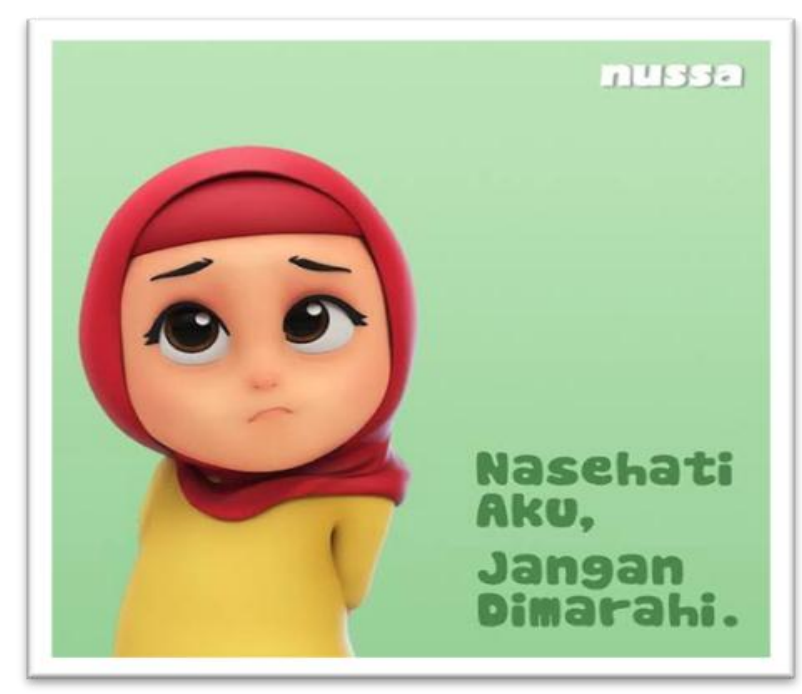

Gambar 3. Tokoh Rara 
c. Uma

Digambarkan sebagai seorang ibu yang sangat sayang kepada anaknya. Dia adalah ibu dari Nussa dan Rara. Tidak hanya sangat sayang kepada anaknya dia juga karakter yang sholehah.

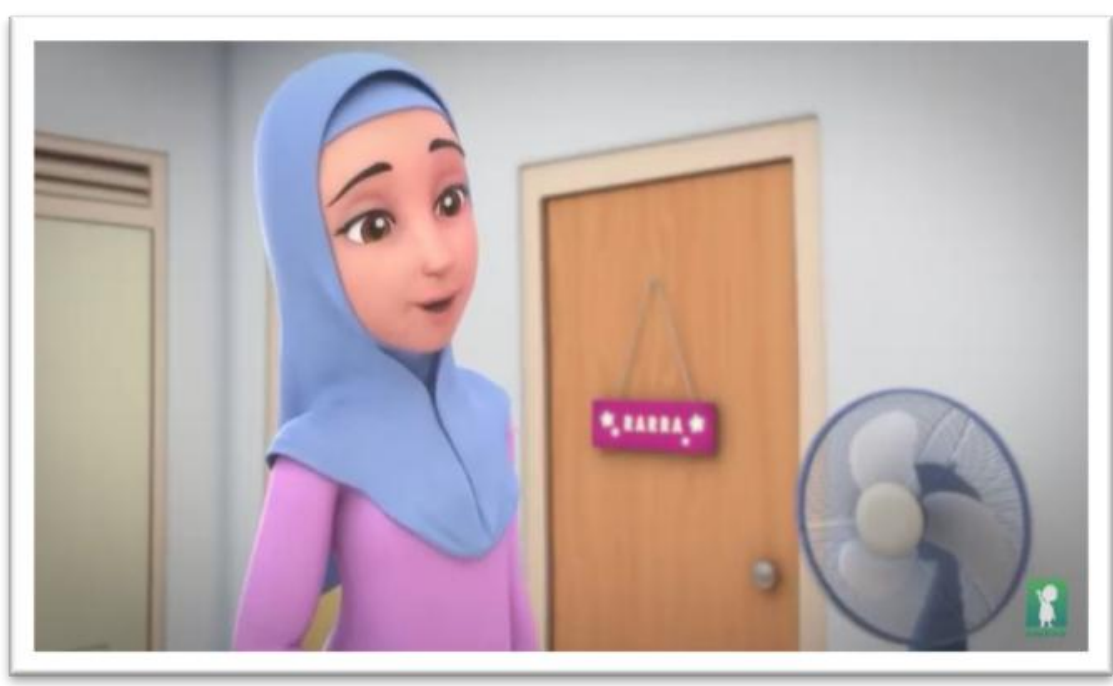

Gambar 4. Tokoh Uma

d. Tante Dewi

Digambarkan sebagai seorang ibu guru muda yang sangat menyenangkan dan asyik. Dia adalah adik kandung dari uma.

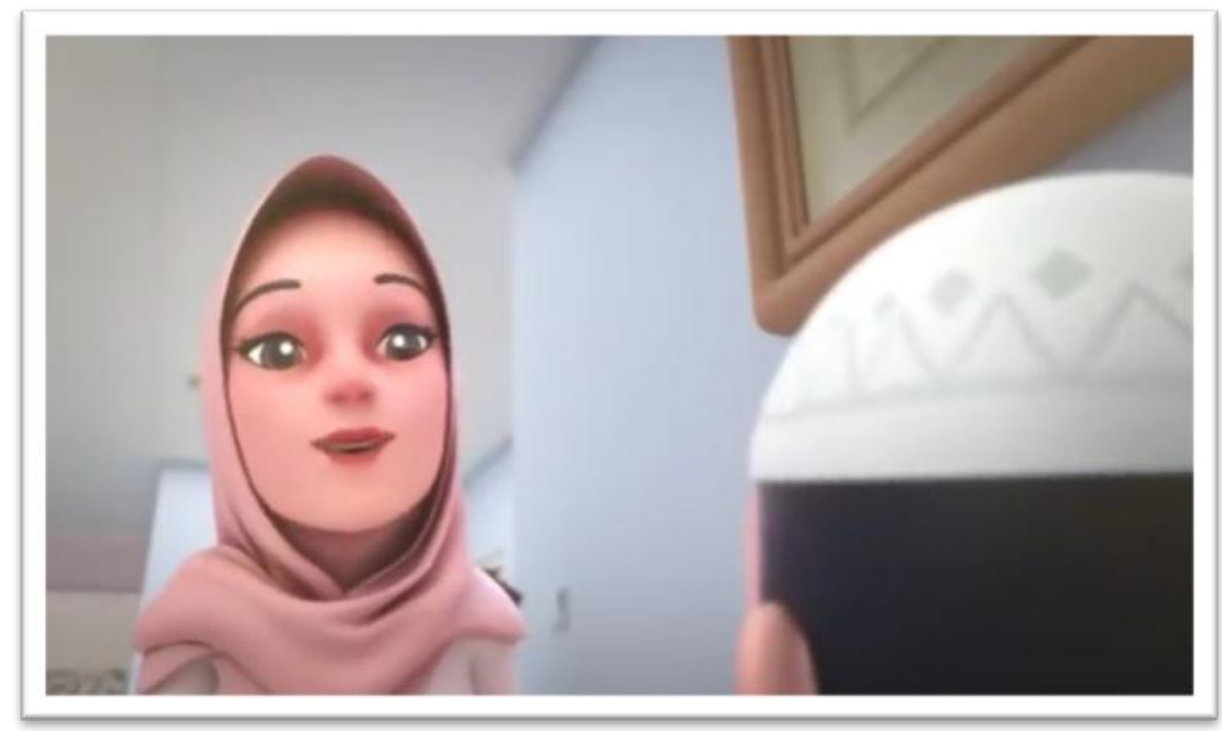

Gambar 5. Tokoh Tante Dewi 
Sebagai gambaran, di bawah ini disajikan ringkasan cerita untuk empat episode yang menjadi objek kajian.

a. Ringkasan Episode "Belajar Ikhlas"

Dalam episode ini ketika Nussa sedang belajar atau mengerjakan PR tibatiba Rara datang dengan wajah yang manyun sedikit menahan sebel dengan temannya. Kakak Nusa pun curiga kenapa Rara begitu. Kemudian Nussa tanya kepada Rara kenapa kok bisa begitu. Ternyata karena ketika di sekolahan tadi rara mengajari temannya membuatkan kelinci dari kertas yang kemudian dikumpulkan. Kemudian hasil nilainya malah lebih bagus teman Rara daripada Rara. Yang bikin Rara tambah sebel lagi temannya bukan mengucap terimakasih malah ngatain bahwa kelincinya Rara jelek.

Setelah Rara ketemu dengan kakak Nussa dan menceritakan kesebelannya tadi kemdian Rara diberi nasehat oleh Nussa agar belajar ikhlas karena ketika kita berbuat tapi masih mengharapkan ikhlas itu berarti belum ikhlas. Nussa belajar ikhlas dari Uma nya yang mana dia ikhlas menerima takdir Allah bahwa Nussa anaknya menyandang disabilitas. Sedikit patah kata Nusa "Uma aja ikhlas menerima Nussa kayak gini berarti Nussa harus lebih ikhlas dong menerima takdir Allah". Setelah Rara sudah paham tentang arti ikhlas, Nussa menyuruh Rara untuk mengambilkan minum. Kemudian ditanya Rara "kok Nussa nyuruhnyuruh" dijawab Nusa "kan tadi udah belajar Ikhlas" kemudian di balik dengan perkataan Rara" berarti kakak Nussa ngajarinnya belum ikhlas dong hehe"

b. Ringkasan Episode "Dahsyatnya Basmallah"

Suatu hari Nussa dan Rara hendak bersepeda. Tidak hanya berdua, mereka mengajak kucingnya yang bernama Antta. Ketika semua keamanan sudah terpakai, mereka tancap gas untuk memulai bersepeda. Selang beberapa saat tiba-tiba ada setan mengganggu Antta dari belakang. Karena hal tu Antta hendak mengusir setan ersebut agar tidak mengganggu. Yang terjadi ketika si Antta berusaha mengusir malah sepeda yang di naiki menjadi tidak stabil dan sampai terjatuh mereka karena kebetulan Nussa juga ngebut dalam mengemudi sepedanya. Setelah di ingat kenapa bisa terjadi seperti itu, ternyata karena Nussa dan Rara tidak membaca bismillah ketika hendak bersepeda tadi sehingga setan mengganggu dari belakang. Kemudian setelah sadar, mereka membaca bismillah bersama-sama. Setelah mereka membaca bismillah bersama-sama setan yang tadinya mengganggu terbakar dan menjadi sangat kecil seperti nyamuk.

c. Ringkasan Episode "Senyum itu Sedekah"

Suatu hari, Nussa Rara dan Uma hendak bersedekah ke panti asuhan. Kemudian rara bingung mau mengasih barang apa untuk disedekahkan. Hingga 
ketemu boneka kesayangan rara yang hendak disedekahkan. Ketika rara manismanisan pamitan dengan boseka kesayangannya lantaran hedak disedekahkan tiba-tiba Uma berkata "Rara Nussa mainan yang d berikan yang bagus ya jangan rusak". Seketika itu boneka kesayangan Rara tiba-tiba rusak.

Sampai di panti asuhan Nussa dan Uma pamitan dengan pengasuhnya dan diberi ucapan terimakasih. Nussa bingung karena Rara tidak ada bersama dia dan Uma. Setelah dicari ternyata Rara sedang senyum-senyum bersama anak panti. Ditanya sama Nussa "Rara kamu ngapain?" rara menjawab "Rara sedang sedekah, kan senyum juga sedekah hehe". Kemudian Nussa pun tertawa melihat tingkah Rara yang menggemaskan itu. Melihat hal itu Nussa malah ikut Rara memberi sedekah lewat senyuman kepada anak-anak panti. Semua yang melihatnya tertawa bahagia.

d. Ringkasan Episode "Bukan Mahram"

Suatu saat ketika Uma sedang membersihkan rumah tiba-tiba ada seseorang yang megetok pintu. Setelah di buka ternyata yang mengetok pintu adalah Dewi adik kandung Uma. Dewi pergi bertugas ketika Rara dan Nussa masih kecil sehingga ketika dia bertemu Rara dan Nussa sangat pangling. Rara pun ketika di peluk tante Dewi juga berfikir siapa sebenarnya yang memeluk dia. Tidak hanya Rara, Nussa pun juga berfikir siapakah wanita itu. Karena Nussa belum tau siapa wanita itu jadinya Nussa menolak ketika di ajak bersalaman oleh tante dewi dengan alasan bukan mahram. Kemudian karena Nussa bingung dengan sesosok wanita tadi, da menanyakan kepada Rara tentang tante dewi. Rara menjawab pernah ketemu dan bahkan dia dulu di gendong ketika bayi. Kemudian Rara menanya kepada Nussa kenapa tidak salaman dengan tante Dewi di jawab oleh Nussa bukan muhrim katanya.

Kemudian Uma bersama tante Dewi mengklarifikasi kebingungan Nussa tersebut. Kemudian Uma menceritakan bahwa tante Dewi adalah adik kandungnya dan mahram untuk Nussa. Mendengar hal itu kemudian Nussa langsung bersalaman dengan tante Dewi. Setelahnya tante dewi memberikan hadiah yang telah dibawanya untuk Nussa dan rara. Rara dan Nussa sangat suka dengan hadiah yang diberikan oleh tante Dewi. Kemudian Rara, Nussa, Uma dan tante Dewi berfoto bersama.

Di samping pemaparan di atas, perlu disinggung disini bahwa kajian pada tulisan ini merupakan hasil penelitian kualitatif tentang sebuah subjek secara mendalam. Jenis penelitian ini adalah penelitian deskriptif analitis, digunakan untuk melacak peristiwa atau menemukan pengetahuan seluas luasnya terhadap obyek penelitian pada suatu saat tertentu. Dalam konteks ini, penelitian ditujukan untuk mendapatkan pengetahuan seluas-luasnya dan dapat memberikan informasi 
tentang sejumlah nilai pendidikan karakter yang ada di dalam film Nussa yang dapat ditanamkan kepada anak usia dini. Secara garis besar, data yang digunakan dalam penelitian ini ada dua, data primer dan sekunder. Data primer berupa empat episode dari film Nussa yang diperoleh dari Youtube. Pemilihan sampel dilakukan secara acak. Data sekunder berupa studi kepustakaan yang digunakan untuk mengumpulkan data-data yang bersifat pustaka sebagai landasan maupun kajian teoritis dan kerangka berpikir.

Analisis data yang digunakan adalah analisis isi yang mencakup tiga subproses yang saling berkaitan satu sama lain, yaitu reduksi data (data reduction), penyajian data (data display), dan penarikan kesimpulan (conclusion drawing/verification).

\section{Nilai-nilai Pendidikan Karakter dalam Film "Nussa"}

Setelah mencermati episode "Belajar Ikhlas", ada beberapa nilai karakter yang dapat ditanamkan kepada anak usia dini. Nilai-nilai tersebut dapat dilihat pada Tabel 2 .

Tabel 2

Nilai karakter pada episode "Belajar Ikhlas"

\begin{tabular}{|l|l|l|}
\hline No. & \multicolumn{1}{|c|}{ Nilai Karakter } & \multicolumn{1}{c|}{ Deskripsi } \\
\hline 1 & $\begin{array}{l}\text { Bersahabat/ } \\
\text { komunikatif }\end{array}$ & $\begin{array}{l}\text { Rara mengajari temannya membuat } \\
\text { kelinci dari kertas }\end{array}$ \\
\hline 2 & Peduli sosial & $\begin{array}{l}\text { Nussa memberi motivasi kepada Rara } \\
\text { yang sebel dengan temannya }\end{array}$ \\
\hline 3 & Jujur & $\begin{array}{l}\text { Sedikit patah kata Nussa "Uma aja } \\
\text { ikhlas menerima Nussa kayak gini } \\
\text { berarti Nussa harus lebih ikhlas dong } \\
\text { menerima takdir Allah". }\end{array}$ \\
\hline 4 & Religius & $\begin{array}{l}\text { Rara belajar ikhlas bahwa memberi } \\
\text { tanpa mengharap }\end{array}$ \\
\hline
\end{tabular}

Sementara itu, nilai-nilai karakter yang terdapat di dalam episode "Dahsyatnya Basmallah" dapat ditanamkan kepada anak usia dini bisa dilihat di Tabel 3.

Tabel 3

Nilai karakter pada episode "Dahsyatnya Basmallah"

\begin{tabular}{|l|l|l|}
\hline No. & \multicolumn{1}{|c|}{ Nilai Karakter } & \multicolumn{1}{c|}{ Deskripsi } \\
\hline 1 & Peduli sosial & $\begin{array}{l}\text { Nussa menanyakan tentang keamanan } \\
\text { berkendara kepada penumpangnya }\end{array}$ \\
\hline 2 & Disiplin \& religius & $\begin{array}{l}\text { Hendaknya mengucapkan basmallah } \\
\text { ketika melakukan apapun }\end{array}$ \\
\hline 3 & Tanggung jawab \& religius & Setelah jatuh dari sepeda lantaran \\
\hline
\end{tabular}




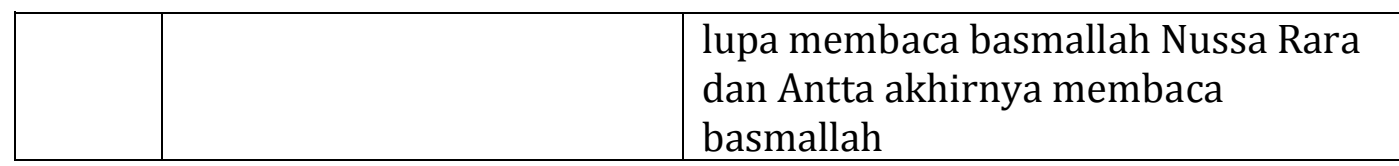

Selanjutnya, nilai-nilai karakter yang terdapat di dalam episode "Senyum itu Sedekah" dan dapat ditanamkan kepada anak usia dini bisa diamati di Tabel 4.

Tabel 4

Nilai karakter pada episode "Senyum itu Sedekah"

\begin{tabular}{|l|l|l|}
\hline No. & \multicolumn{1}{|c|}{ Nilai Karakter } & \multicolumn{1}{c|}{ Deskripsi } \\
\hline 1 & Kerja keras \& mandiri & $\begin{array}{l}\text { Uma, Nussa, dan Rara masing-masing } \\
\text { menyiapkan barang pribadinya untuk } \\
\text { disumbangkan ke panti asuhan }\end{array}$ \\
\hline 2 & Religius \& peduli sosial & $\begin{array}{l}\text { Mendoakan agar barang yang } \\
\text { diberikan bermanfaat }\end{array}$ \\
\hline 3 & Religius & $\begin{array}{l}\text { Didoakan kembali agar semua } \\
\text { kebaikan dibalas sama Allah }\end{array}$ \\
\hline 4 & Kreatif & $\begin{array}{l}\text { Rara yang tidak mempunyai barang } \\
\text { untuk bersedekah akhirnya dia } \\
\text { bersedekah lewat senyuman. }\end{array}$ \\
\hline 5 & Menghargai prestasi & $\begin{array}{l}\text { Nussa ikut bahagia melihat sedekah } \\
\text { yang diberikan Rara. Semua yang } \\
\text { melihatnya pun merasa senang. }\end{array}$ \\
\hline
\end{tabular}

Sedangkan diantara nilai-nilai karakter yang terdapat didalam episode "Bukan Mahram" dan dapat ditanamkan kepada anak usia dini bisa dicermati di Tabel 5.

Tabel 5

Nilai karakter pada episode "Bukan Mahram"

\begin{tabular}{|l|l|l|}
\hline No. & \multicolumn{1}{|c|}{ Nilai Karakter } & \multicolumn{1}{c|}{ Deskripsi } \\
\hline 1 & Religius & $\begin{array}{l}\text { Tante Dewi mengucap salam ketika } \\
\text { mengetuk pintu }\end{array}$ \\
\hline 2 & Religius & $\begin{array}{l}\text { Nussa mengucap salam ketika masuk } \\
\text { rumah }\end{array}$ \\
\hline 3 & Menghargai prestasi & $\begin{array}{l}\text { Tante Dewi memberikan hadiah } \\
\text { kepada Nussa dan rara }\end{array}$ \\
\hline 4 & Religius & $\begin{array}{l}\text { Tidak boleh bersentuhan apabila } \\
\text { bukan mahram }\end{array}$ \\
\hline 5 & Peduli sosial & Menghormati tamu \\
\hline
\end{tabular}

Setelah memperhatikan pemaparan di atas, dapat dikatakan bahwa film Nussa dapat menjadi sarana/media pendidikan karakter bagi anak usia dini di lembaga PAUD, baik di TK/RA, maupun di Kelompok Bermain dan Tempat Penitipan Anak. Sebagaimana ditegaskan di dalam Pasal 3 Ayat 2 UU RI No. 8 
Tahun 1992 tentang Perfilman, perfilman di Indonesia diarahkan kepada pembangunan watak dan kepribadian bangsa serta peningkatan harkat dan martabat manusia.

Meskipun tidak semua karakter muncul di empat episode tersebut, paling tidak nilai-nilai karakter yang dapat ditanamkan kepada anak usia dini sudah tampak. Penanaman nilai-nilai itu kemudian dapat dikembangkan oleh guru PAUD sesuai dengan konteks yang ada. Misalnya, karakter "Peduli sosial" dapat ditanamkan ketika ada momen makan bersama. Jika ada anak yang lupa tidak membawa bekal, guru bisa meminta anak-anak yang lain untuk berbagi dengan teman yang saat itu tidak membawa makanan. Contoh berikutnya, karakter "religius" dapat ditanamkan kepada anak-anak dengan cara membaca basmallah ketika hendak melakukan apapun. Contoh lain, karakter "Tanggung jawab" dapat ditanamkan kepada anak-anak dengan cara mengembalikan alat permainan ke tempat semula seusai kegiatan pembelajaran. Dengan begitu, semua karakter diharapkan melekat sejak dini hingga anak-anak menjadi dewasa dan tidak terjadi lagi hal-hal yang tidak diinginkan sebagaimana kasus-kasus yang diterangkan di muka.

\section{Simpulan}

Berdasarkan pemaparan di atas, dapat disimpulkan bahwa film Nussa sangat kental dengan nilai-nilai karakter baik yang sifatnya Islami ataupun karakter secara umum. Diantara nilai-nilai pendidikan karakter yang muncul pada empat episode film Nussa yang juga dapat ditanamkan pada anak usia adalah religius, kerja keras, mandiri, bersahabat dan komunikatif, jujur, peduli sosial, kreatif, disiplin, menghargai prestasi, dan tanggung jawab. Dari hasil analisis tersebut diharapkan orang tua dapat memberikan asupan informasi melalui serial film yang mendidik salah satunya film Nussa. Dengan asupan informasi yang syarat akan nilai-nilai karakter diharapkan anak didik usia dini mampu berkembang dengan baik sesuai dengan fitrahnya serta memiliki karakter yang kuat. Terutama dalam karakter tentang religius harus lebih ditekankan sejak dini agar menjadi pondasi karakter yang kuat. Tidak hanya itu peran orang tua dan guru juga sangat penting untuk membimbing dalam kebaikan dan juga mencontohkan kebaikan.

\section{Daftar Rujukan}

Britton, Lesley. 1992. Montessori Play and Learn: A Parents' Guide to Purposeful Play from Two to Six. New York: Crown Publishers Inc.

Darmu'in. 2013. Kurikulum Pendidikan Karakter di Taman Kanak-kanak Pembina Semarang. Nadwa: Jurnal Pendidikan Islam, Vol. 7, No. 1, April 2013. 
Dirjen PAUDNI Kemdiknas. 2012. Pedoman Pendidikan Karakter pada Pendidikan Anak Usia Dini. Jakarta: Direktorat Pembinaan PAUD Kemdiknas.

Gunawan, Heri. 2012. Pedidikan Karakter Konsep dan Implementasi. Bandung: Alfabeta.

Hidayati, Siti Nurul Nur. 2016. Meningkatkan Kemampuan Berbicara melalui Media Film Kartun "Adit dan Sopo Jarwo" pada Anak Kelompok A di TK Salma Insani Kota Kediri Tahun Pelajaran 2014/2015 [Skripsi]. Kediri: PGPAUD FKIP Universitas Nusantara PGRI.

Ismail \& Hidayatulloh, M. Agung. 2014. Learning to live together: Penanaman karakter pada anak usia dini di lembaga PAUD Islam. Al-Ulum, Vol. 14, No. 1, Juni 2014, hlm. 229-246.

Kemendiknas. 2010. Buku Induk Pendidikan Karakter. Jakarta: Kementerian Pendidikan Nasional.

Koesmana, A.D. 2012. Pendidikan Karakter Utuh dan Menyeluruh. Yogyakarta: Kanisius.

Muslich, Masnur. 2011. Pendidikan Karakter: Menjawab Tantangan Krisis Multidimensional. Jakarta: Bumi Aksara. Nurkamto, Joko. 2011. Pendidikan Karakter di Sekolah [makalah diskusi Program Doktor Ilmu Pendidikan UNS]. Solo: UNS.

Pusat Kurikulum. 2010. Pengembangan Budaya dan Karakter Bangsa: Pedoman Sekolah. Jakarta: Badan Penelitian dan Pengembangan Kemdiknas.

Risnawati, Vivit. 2012. Optimalisasi Pendidikan Karakter Anak Usia Dini melalui Sentra Min Peran Taman Kanak-kanak Padang. Jurnal Pesona PAUD, Vol. 1, No. 1, 2012.

Salim, Peter dan Yenny Salim. 2002. Kamus Bahasa Indonesia Kontemporer. Jakarta: Modern Engish Press

Samani, Muchlas dan Hariyanto. 2011. Konsep dan Model Pendidikan Karakter. Bandung: Remaja Rosdakarya.

Undang-undang Republik Indonesia Nomor 20 Tahun 2003 tentang Sistem Pendidikan Nasional.

Undang-undang Republik Indonesia Nomor 32 Tahun 2002 tentang Penyiaran.

Undang-undang Republik Indonesia Nomor 8 Tahun 1992 tentang Perfilman. 